\title{
Efeito da cianogênese na incompatibilidade entre clones de copa de seringueira e o clone de painel IPA $1^{(1)}$
}

\author{
Larissa Alexandra Cardoso Moraes ${ }^{(2)}$, Vicente Haroldo de Figueiredo Moraes ${ }^{(2)}$ \\ e Adônis Moreira(3)
}

\begin{abstract}
Resumo - O objetivo deste trabalho foi verificar o envolvimento dos glicosídeos cianogênicos na incompatibilidade, por translocação, do clone de seringueira IPA 1 com copas enxertadas com clones de outras espécies de Hevea. Determinou-se, na casca dos clones de painel IPA 1, Fx 4098 e Fx 3864, a atividade das enzimas $\beta$-glicosidase, $\beta$-diglicosidase e $\beta$-cianoalaninassintase ( $\beta$-CAS) e o desenvolvimento de combinações de enxertos, tendo como clone de painel o IPA 1 e como copa enxertada, clones de baixo ou alto potencial cianogênico (HCN-p). Dosou-se o HCN-p de folhas jovens e maduras de clones de copa já conhecidos como compatíveis ou incompatíveis. A atividade de $\beta$-CAS no IPA 1 foi baixa, sendo alta no Fx 3864 e intermediária no Fx 4098. Esse fato, associado à maior atividade da $\beta$-glicosidase e $\beta$-diglicosidase encontradas no IPA 1 , confere a este clone extrema sensibilidade ao cianeto. Os enxertos com clones de baixo HCN-p nas folhas jovens mostraram-se compatíveis, bem como com os clones em que o alto $\mathrm{HCN}-\mathrm{p}$ nas folhas jovens permanece alto nas folhas maduras. Os clones incompatíveis apresentaram alto HCN-p nas folhas jovens e significativa redução nas maduras. Essas evidências reforçam a hipótese de a incompatibilidade ser causada pela translocação de linustatina, das folhas dos clones enxertados, para o caule do IPA 1. Os sintomas se assemelham aos de secamento do painel de sangria, indicando o envolvimento da cianogênese na sua evolução.
\end{abstract}

Termos para indexação: enxertia, glicosídeo, linamarase, metabolismo.

\section{Effect of the cyanogenesis on the incompatibility of crow clones of Hevea spp. budded onto IPA 1}

\begin{abstract}
The objective of this work was to verify the role of the rubber tree cyanogenic glycosides in the incompatibility of the IPA 1 clone (Hevea brasiliensis) with budded crowns of clones of other species of Hevea. The activity of the following enzymes involved in the cyanide metabolism was determined: $\beta$-glycosidase, $\beta$-diglycosidase and $\beta$-cyanoalaninesynthase ( $\beta$-CAS). These enzymes were studied in the stem bark of the clones IPA 1, Fx 3864 and Fx 4098. Clones of high and low cyanogenic potential (HCN-p) were crown budded on IPA 1, and the development of the budded plants was recorded. The HCN-p of young and mature leaves of other crown clones known as compatible or incompatible was determined. The $\beta$-CAS activity of IPA 1 was found to be as low as in non-cyanogenic plants while it was very high in Fx 3864 and intermediate in Fx 4098. IPA 1 displayed higher $\beta$-glycosidase and $\beta$-diglycosidase activities, which, together with the very low $\beta$-CAS activity, determine the extreme sensitivity to cyanide of this clone. Crown clones of low HCN-p in young leaves were compatible, as well as those with high HCN-p in young leaves, but keeping it high in the mature. In incompatible clones the HCN-p is reduced in mature leaves. These evidences support the hypothesis that the incompatibility is caused by the translocation of linustatin, from the leaves to the stem of IPA 1. The incompatibility symptoms resemble some aspects of the Tapping Panel Dryness, suggesting a relationship of TPD with cyanogenesis.

Index terms: grafting, glycosides, linamarase, metabolism.
\end{abstract}

(1) Aceito para publicação em 8 de fevereiro de 2002 . Extraído da dissertação de mestrado apresentada pelo primeiro autor à Escola Superior de Agricultura Luiz de Queiroz, Piracicaba, SP.

(2) Embrapa-Centro de Pesquisa Agroflorestal da Amazônia Ocidental (CPAA), Caixa Postal 319, CEP 69011-970 Manaus, AM. E-mail: larissa@cpaa.embrapa.br, vicente@cpaa.embrapa.br
(3) Embrapa-CPAA. adonis@cpaa.embrapa.br

\section{Introdução}

A rara ocorrência de incompatibilidade de enxertia no gênero Hevea facilitou o desenvolvimento da técnica de enxertia de copa com clones de diferentes espécies resistentes ao mal-das-folhas, causado pelo fungo Microcyclus ulei (P. Henn.) v. Arx., que há décadas tem impedido o estabelecimento da cultura na região Amazônica (Moraes, 1997). 
No entanto, em ensaios de testes de clones de copa, constatou-se a incompatibilidade por translocação nas combinações onde o painel foi o clone IPA 1 (H. brasiliensis) e as copas, clones provenientes de $H$. pauciflora e $H$. guianensis var. marginata. $\mathrm{O}$ primeiro sintoma dessa incompatibilidade, em enxertos com três a quatro lançamentos foliares, é a ausência do escoamento do látex no caule do IPA 1, abaixo da união do enxerto, devida à coagulação do látex nos laticíferos, seguindo-se necrose da casca do IPA 1 e a morte do enxerto após o anelamento completo da casca (Moraes \& Moraes, 1996).

O fato de aplicações de soluções de linamarina e cianeto de potássio $(\mathrm{KCN})$ no caule do painel do IPA 1 terem revelado alta sensibilidade e a existência de combinações compatíveis com clones de copa de Hevea nitida CPAA C64 e CPAA C65 (Moraes, 1999) - espécie com potencial cianogênico extremamente baixo (Lieberei, 1988), em comparação com os clones Fx 4098 e Fx 3864 - fortaleceu a hipótese de que os sintomas de incompatibilidade tenham sido provocados por compostos cianogênicos transportados das copas incompatíveis para o painel (Moraes et al., 2001), o que evidencia a necessidade do estudo das enzimas relacionadas com o metabolismo do cianeto.

A linamarina, glicosídeo cianogênico do gênero Hevea, é produzida em grande quantidade pelas folhas jovens, principalmente no estádio $\mathrm{C}$ de desenvolvimento (Dijkman, 1951), e é armazenada no vacúolo. A enzima responsável pela degradação desse glicosídeo e liberação do cianeto (HCN) é a linamarase, localizada exclusivamente no apoplasma, sendo necessário o rompimento do tecido para haver contato entre ela e o substrato (Lieberei, 1988).

O transporte do glicosídeo cianogênico na planta intacta só é possível pela adição de mais uma unidade de glicose à molécula da linamarina, transformando-a no diglicosídeo linustatina, o qual é imune à ação da linamarase apoplásmica, permitindo seu transporte através dos sistemas condutores do vegetal (Selmar, 1993).

Outra enzima envolvida no metabolismo das substâncias cianogênicas é a $\beta$-cianoalaninassintase, que catalisa a reação entre o $\mathrm{HCN}$ e a cisteína, formando $\beta$-cianoalanina e sulfeto de hidrogênio (Floss et al.,
1965; Blumenthal-Goldschmidt et al., 1968; Castric et al., 1972). Esse metabolismo é muito vantajoso para as plantas, já que o produto $\beta$-cianoalanina pode ser metabolizado para asparagina, que, por sua vez, pode ser incorporada no metabolismo geral da planta (Miller \& Conn, 1980). Em espécies nãocianogênicas, a presença dessa enzima está relacionada com o mecanismo de desintoxicação na síntese endógena de etileno, onde há formação de $\mathrm{HCN}$ na fase em que o ácido carboxílico aminociclopropano (ACC) é transformado em etileno (Peiser et al., 1984; Goudey et al., 1989).

O objetivo deste trabalho foi verificar o envolvimento dos glicosídeos cianogênicos da seringueira na incompatibilidade por translocação apresentada pelo clone IPA 1 (Hevea brasiliensis), com copas enxertadas com clones de outras espécies de Hevea.

\section{Material e Métodos}

As coletas e as análises dos materiais vegetais foram realizadas na Embrapa-Centro de Pesquisa Agroflorestal da Amazônia Ocidental (CPAA), Município de Manaus, Estado do Amazonas, situado nas coordenadas $3^{\circ} 8^{\prime} 5^{\prime \prime}$ de LS e $60^{\circ} 1^{\prime} 0^{\prime \prime}$ de LW. As amostras de casca do caule, para determinação da atividade enzimática, foram colhidas do antepenúltimo lançamento de hastes de cerca de um ano, de plantas de jardim clonal, dos clones de $H$. brasiliensis IPA 1, Fx 4098 e Fx 3864; as duas últimas testemunhas são compatíveis com todas as copas enxertadas.

A determinação da atividade de $\beta$-cianoalaninassintase ( $\beta$-CAS) foi feita pelo método descrito por Blumenthal-Goldschmidt et al. (1963). Esse método consiste na determinação da atividade da enzima em um grama de casca do caule em $2 \mathrm{~mL}$ de tampão tris/ $\mathrm{HCl} 50 \mathrm{mmol} \mathrm{L}^{-1}$, pH 8,2 homogeneizada em gral. Após a homogeneização, o material é centrifugado por uma hora, a $20.000 \mathrm{~g}$, entre $0^{\circ} \mathrm{C} \mathrm{e} 6^{\circ} \mathrm{C}$. Transfere-se $1 \mathrm{~mL}$ do sobrenadante para frasco de vidro com capacidade para $30 \mathrm{~mL}$, e adiciona-se $0,5 \mathrm{~mL}$ de KCN, $50 \mathrm{mmol} \mathrm{L}^{-1}$, diluído em tampão tris $50 \mathrm{mmol} \mathrm{L}^{-1}$, pH 8,2, e em seguida, $0,5 \mathrm{~mL}$ de l-cisteína, $10 \mathrm{mmol} \mathrm{L}^{-1}$, diluída no mesmo tampão, e, posteriormente, incuba-se por 30 minutos a $30^{\circ} \mathrm{C}$. Em seguida, acrescenta-se à mistura $0,5 \mathrm{~mL}$ de N-N-dimetil-p-fenilenodiamina $20 \mathrm{mmol} \mathrm{L}^{-1}$, em $\mathrm{HCl} 7,2 \mathrm{~mol} \mathrm{~L}^{-1}$, e $0,5 \mathrm{~mL}$ de $\mathrm{FeCl}_{3}$, $30 \mathrm{mmol} \mathrm{L}^{-1}$, em HCl 1,2 $\mathrm{mol} \mathrm{L}^{-1}$, obtendo-se um volume final de $3 \mathrm{~mL}$. Deixa-se em repouso por 20 minutos a $30^{\circ} \mathrm{C}$, depois da centrifugação a $1.000 \mathrm{~g}$, por 10 minutos. 
As leituras de absorvância a $650 \mathrm{~nm}$ foram comparadas com curva-padrão de $\mathrm{Na}_{2} \mathrm{~S}$, de $0,04 \mathrm{mmol} \mathrm{L}^{-1}$ a $0,167 \mathrm{mmol} \mathrm{L}^{-1}$, a partir de solução-estoque de $\mathrm{Na}_{2} \mathrm{~S}$ $\left(0,1 \mathrm{~mol} \mathrm{~L}^{-1}\right)$, titulada por iodometria, após precipitação do sulfeto com cloreto de zinco amoniacal (Scott, 1939; Morita \& Assumpção, 1990). Os resultados em absorbância foram convertidos em nmol $\mathrm{H}_{2} \mathrm{~S}^{-} \mathrm{s}^{-1} \mathrm{~g}^{-1}$.

Na determinação da atividade das enzimas $\beta$-glicosidase (linamarinase) houve o seguinte procedimento (Selmar, 1986): $1 \mathrm{~g}$ de casca do último lançamento, com folíolos maduros, foi recortado em pedaços retangulares de aproximadamente $2 \times 3 \mathrm{~mm}$, e moída em gral de porcelana pré-resfriado, com $4 \mathrm{~mL}$ de $\mathrm{NaH}_{2} \mathrm{PO}_{4}, 0,067 \mathrm{~mol} \mathrm{~L}^{-1}$. $\mathrm{O}$ extrato foi decantado após compressão do resíduo fibroso, que foi moído novamente com $5 \mathrm{~mL}$ de $\mathrm{NaH}_{2} \mathrm{PO}_{4}$, $0,067 \mathrm{~mol} \mathrm{~L}^{-1}$. O extrato final, livre da maior parte do resíduo fibroso foi centrifugado a $20.000 \mathrm{~g}$ por 1 hora, entre $0^{\circ} \mathrm{C}$ e $6^{\circ} \mathrm{C}$. O sobrenadante foi filtrado em membrana Milipore, sob pressão de 2,5 bárias, e lavado três vezes, com filtração nas mesmas condições, com $30 \mathrm{~mL}$ de tampão de fosfato, pH 6,5, $10 \mathrm{mmol} \mathrm{L}^{-1}$, a cada lavagem, para eliminação de pigmentos e possíveis inibidores da enzima. $O$ volume final do extrato foi reduzido para $5 \mathrm{~mL}$, na última filtração, e guardado em geladeira. Após a confecção do extrato, determinou-se a atividade da enzima $\beta$-glicosidase (linamarinase), com a retirada de $0,1 \mathrm{~mL}$ do extrato e diluído em 2,4 mL de água destilada e $0,5 \mathrm{~mL}$ de p-nitrofenilglicopiranosídeo $\left(20 \mathrm{mmol} \mathrm{L}^{-1}\right)$ a pH 5,6 e adição de $2 \mathrm{~mL}$ de $\mathrm{Na}_{2} \mathrm{CO}_{3}, 0,5 \mathrm{~mol} \mathrm{~L}^{-1}$, a fïm de paralisar a atividade da enzima e evidenciar a coloração do p-nitrofenol liberado. A leitura da absorbância foi feita a $400 \mathrm{~nm}$, e calculada a quantidade de p-nitrofenol liberado por grama de matéria fresca de casca por minuto.

A determinação da $\beta$-diglicosidase (linustatinase) foi feita nos extratos da enzima, de acordo com o método descrito por Selmar (1986), através do meio de incubação com $2 \mathrm{~mL}$ de amigdalina, 12,4 $\mathrm{mol} \mathrm{L}^{-1}$, em tampão McIlvaine (1921) $50 \mathrm{mmol} \mathrm{L}^{-1}, \mathrm{pH} 4,5$ e $0,5 \mathrm{~mL}$ do extrato da enzima. A mistura foi incubada durante 1 hora, a $30^{\circ} \mathrm{C}$. A reação foi interrompida pela adição de $1 \mathrm{~mL}$ de $\mathrm{NaOH}$ $1 \mathrm{~mol} \mathrm{~L}^{-1}$, acrescentando-se $0,5 \mathrm{~mL}$ de tampão MacIlvaine (1921) $50 \mathrm{mmol} \mathrm{L}^{-1}$, pH 7 e $1 \mathrm{~mL}$ de $\mathrm{HCl} 1 \mathrm{~mol} \mathrm{~L}-1$, procedendo-se, em seguida, a reação de coloração com kit Spectroquant da Merck, para dosagem de cianeto em solução. A leitura da absorbância foi feita a $585 \mathrm{~nm}$, e convertidas em nmol $\mathrm{CN}^{-1} \mathrm{~h}^{-1} \mathrm{~g}^{-1}$.

No teste de enxertia de clones de copa de baixo potencial cianogênico, no clone IPA 1, foram utilizados os clones Fx 4512 (H. benthamiana), PL 22 (H. pauciflora), PUA 5 (H. pauciflora) e PUA 9 (H. pauciflora), cujo potencial cianogênico (HCN-p) é muito baixo (Lieberei, 1988), e, como contraprova, o clone CPAA C 13 (H. pauciflora $\mathrm{x}$ H. guianensis var. marginata). Essas enxertias foram efetuadas em ramos laterais de plantas de IPA 1 decapitadas em jardim clonal.

A partir dos primeiros sintomas de incompatibilidade nas folhas dos enxertos de copa, até o aparecimento de lesões necróticas no porta-enxerto, foram colhidos segmentos de aproximadamente $3 \times 15 \mathrm{~mm}$, da casca do caule do IPA 1, abaixo da placa do enxerto, fixados em FAA e seccionados a mão livre no sentido longitudinal radial. As lâminas com os cortes em água destilada e cobertas com lamínula foram observadas ao microscópio ótico, com ocular 18x e objetivas $25 \mathrm{x}$ ou $40 \mathrm{x}$.

O potencial cianogênico (HCN-p) de clones de copa de seringueira foi determinado em folhas jovens (estádio C) e maduras (penúltimo lançamento) dos clones de painel IPA 1 (H. brasiliensis) e de copa IAN 6158 (H. brasiliensis x H. benthamiana), Fx 985 (H. brasiliensis) e CPAA C 65 (H. nitida), CPAA C 06 (H. pauciflora), CPAA C 13 (H. pauciflora $\times$ H. guianensis var. marginata), CPAA C 14 (H. pauciflora $\times$ H. guianensis var. marginata), CPAA C 50 (H. pauciflora $\mathrm{x}$ H. rigidifolia), CBA 1 (H. pauciflora) e CNS G 124 (H. pauciflora).

O método de determinação do HCN-p das folhas foi adaptado por Lieberei (1986) e Selmar (1986). A glicosidase obtida das folhas da seringueira e utilizada para liberação total do cianeto, na dosagem do HCN-p das folhas, foi parcialmente dessalinizada por meio da lavagem com tampão fosfato, $\mathrm{pH} 6,5,10 \mathrm{mmol} \mathrm{L}^{-1}$, com filtração em membrana Milipore, tipo PTGC, sob pressão constante de 2,5 bárias. O tampão fosfato foi adicionado em parcelas de $50 \mathrm{~mL}$, a cada lavagem, consumindo-se um total de $300 \mathrm{~mL}$. Após a adição dos últimos $50 \mathrm{~mL}$ de tampão, a filtração sob pressão continuou até atingir o volume de $15 \mathrm{~mL}$. A lavagem da proteína com o tampão permitiu também a eliminação do cianeto presente nas folhas de seringueira, cujo conteúdo foi determinado de acordo com Selmar (1986).

Para maior segurança quanto ao desempenho da enzima extraída, fez-se um teste de sua capacidade de hidrólise com solução de linamarina na concentração de 0,238 $\mathrm{mg} \mathrm{mL}^{-1}$, correspondendo a $25,04 \mathrm{mg} \mathrm{L}^{-1}$ de $\mathrm{CN}^{-}$, determinando-se o cianeto liberado de acordo com Selmar (1986), e obteve-se o valor esperado com a hidrólise completa do glicosídeo pela ação da enzima adicionada ao meio de reação.

As determinações da atividade das enzimas e do HCN-p das folhas de seringueira foram realizadas em três repetições, e cada planta constituiu uma repetição; todas foram escolhidas ao acaso. Os resultados foram submetidos à 
análise de variância (teste F), e as médias, comparadas pelo teste de Tukey a $1 \%$ de probabilidade (Pimentel-Gomes, 1990).

\section{Resultados e Discussão}

A atividade da $\beta$-CAS do IPA 1 $\left(0,015 \mathrm{nmol} \mathrm{H}_{2} \mathrm{~S} \mathrm{~s}^{-1} \mathrm{~g}^{-1} \pm 0,007\right)$ foi sete vezes menor do que a do $\mathrm{Fx} 4098$, e 13 vezes menor, em comparação com a atividade do Fx 3864 (Figura 1). Esses resultados corroboram a hipótese de que no IPA 1 a fixação do cianeto em compostos não-cianogênicos é menos eficiente do que nos demais clones testados; este resultado é coerente com os de Moraes et al. (2001), com relação aos teores mais elevados de HCN livre encontrados nesse clone após a aplicação de linamarina, bem como com a sua extrema sensibilidade ao cianeto, se comparada à do Fx 3864.

Os valores de atividade de $\beta$-CAS dos clones Fx 3864 e Fx 4098 são da mesma ordem de grandeza dos relatados por Umbach (1989), e explicam também as diferenças de resposta ao $\mathrm{KCN}$ e à linamarina, entre o Fx 4098 e o Fx 3864 observadas por Moraes et al. (2001). A atividade muito baixa de $\beta$-CAS encontrada no IPA 1 é um exemplo extremo da variação de atividade dessa enzima, observada também por Umbach (1989) em diferentes espécies de Hevea. Além disso, é equivalente à de espécies não-cianogênicas (Miller \& Conn, 1980). Esses níveis de atividade são suficientes apenas para a fixação de pequena quantidade de HCN liberada na síntese de etileno.

A atividade de $\beta$-glicosidase na casca do caule no clone IPA 1 foi de 7,12 $\pm 0,66 \mu \mathrm{mol} \mathrm{p}-\mathrm{NP} \mathrm{g}^{-1} \mathrm{~min}^{-1}$, valor duas vezes maior que os encontrados nos clones Fx 4098 e Fx 3864 (Figura 1). Cerca de 17\% da atividade enzimática foi encontrada no filtrado dos extratos dos três clones, o que indica que a membrana utilizada é permeável pelo menos para a forma monomérica da enzima. A atividade mais alta de $\beta$-glicosidase encontrada no caule do IPA 1 comprova sua alta capacidade de hidrolisar linamarina. Esse fato, associado à atividade muito baixa de $\beta$-CAS, acarreta numa maior concentração de $\mathrm{HCN}$ livre (Moraes et al., 2001), após aplicação de soluções de linamarina no caule desse clone.

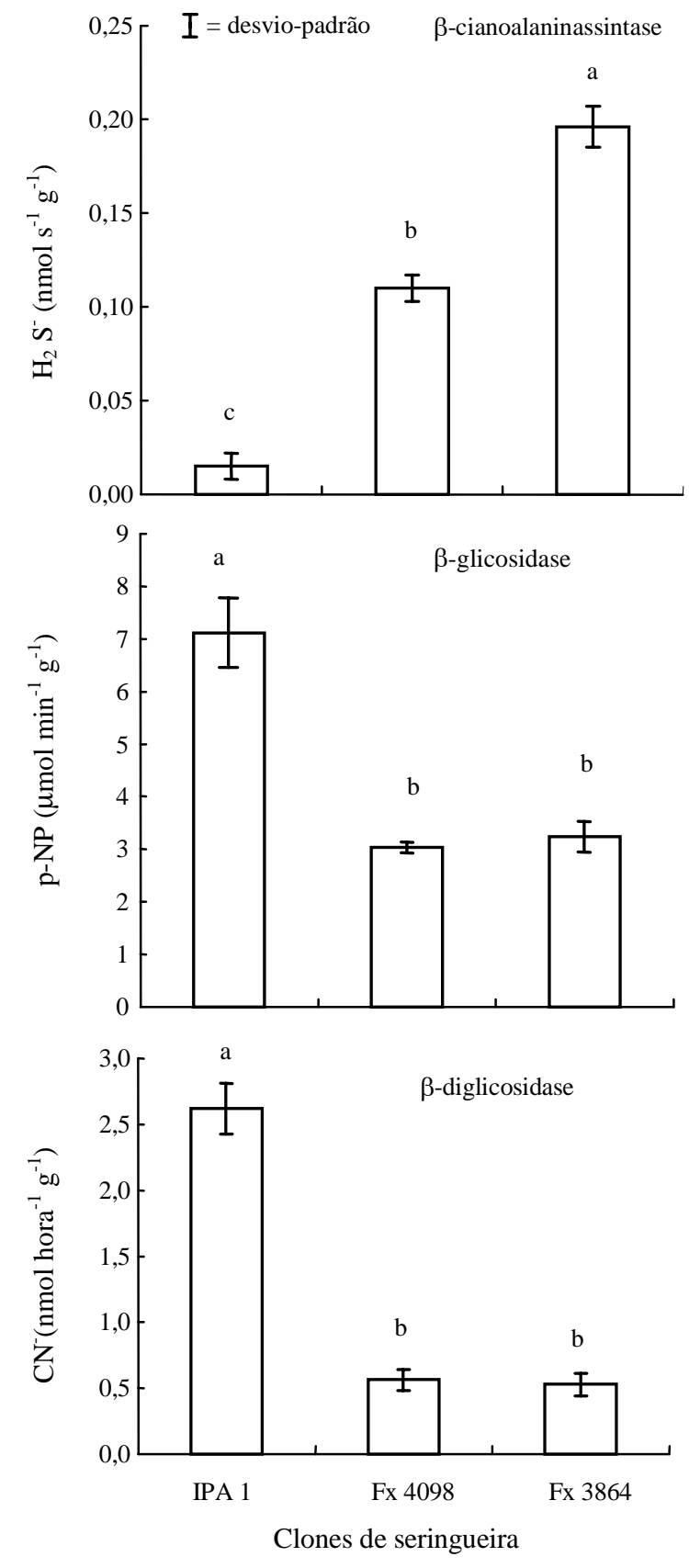

Figura 1. Atividades da $\beta$-cianoalaninassintase, $\beta$-glicosidase e $\beta$-diglicosidase, medidas pelo tiossulfato $\left(\mathrm{H}_{2} \mathrm{~S}\right)$, p-nitrofenol (p-NP) e cianeto $\left(\mathrm{CN}^{-}\right)$, respectivamente, na casca dos clones IPA 1, Fx 4098 e Fx 3864. Médias com letras distintas diferem entre si a $1 \%$ de probabilidade pelo teste de Tukey. 
A atividade da $\beta$-diglicosidase na casca do caule do IPA $1\left(2,620 \mathrm{nmol} \mathrm{CN}^{-1}\right.$ hora $\left.^{-1} \mathrm{~g}^{-1} \pm 0,190\right)$ foi cerca de quatro vezes maior que os valores obtidos em relação aos clones Fx 4098 e Fx 3864 (Figura 1). Comparando-se os resultados dos tratamentos de linamarina com os de enxertia com clones incompatíveis, observa-se uma grande diferença de intervalo de tempo entre a coagulação do látex e a necrose da casca do IPA 1 (Tabela 1); tal fato pode estar relacionado à atividade das enzimas envolvidas, ou seja: a maior atividade da $\beta$-glicosidase, liberando mais rapidamente a linamarina aplicada, apressaria o surgimento dos sintomas, enquanto nos enxertos o constante transporte em baixa concentração da linustatina, aliado à baixa atividade da $\beta$-diglicosidase, aumentaria esse intervalo. A atividade da $\beta$-diglicosidase, mais alta no IPA 1, comparada à dos outros dois clones, reforça a hipótese da ação da cianogênese na incompatibilidade desse clone com copas enxertadas de vários clones.

Nos enxertos dos clones considerados de baixo HCN-p (FX 4512, PL 22, PUA 5 e PUA 9) (Lieberei, 1986), as brotações desenvolveram-se normalmente e não houve redução do escoamento do látex ou qualquer outro sintoma de incompatibilidade por translocação no IPA 1, abaixo dos enxertos em crescimento.

Os enxertos do clone CPAA C 13 inicialmente apresentaram aspecto sadio e vigoroso, superando, em alguns casos, os clones de baixo HCN-p. Porém, a partir do segundo lançamento do enxerto, deixou de escoar látex no IPA 1, inicialmente cerca de $10 \mathrm{~cm}$ abaixo da placa do enxerto, e, posteriormente, até no caule principal decapitado, com cerca de $3 \mathrm{~cm}$ de diâmetro. No início do terceiro lançamento, passou a ser verificada necrose da casca do ramo lateral enxertado, a partir das proximidades da placa de enxerto, estendendo-se para baixo até o caule principal. As folhas do enxerto tornaram-se cloróticas, murcharam, e em seguida apresentaram secamento progressivo, sete dias após a necrose da casca ter atingido um anelamento completo. Sintomas semelhantes foram descritos por Moraes \& Moraes (1996), quando se observou a incompatibilidade por translocação pela primeira vez em Hevea.

Em cortes da casca do caule foi também verificada a coagulação do látex nos laticíferos, e a presença de células com inclusão de tanino. No tecido necrótico acumulou-se uma substância escura, semelhante à descrita na síndrome do secamento de painel de sangria (Faÿ \& Hébant, 1980). Tais sintomas de incompatibilidade foram mais nítidos que nas primeiras observações de sua ocorrência, sendo, portanto, idênticos aos produzidos pela aplicação de linamarina, e, em parte, pela aplicação de KCN (Moraes et al., 2001), exceto quanto ao intervalo entre a coagulação do látex nos laticíferos e o aparecimento da necrose em toda a espessura da casca.

Para permitir a comparação entre o HCN-p de folhas no estádio C com o de folhas maduras, os dados

Tabela 1. Efeito de doses de linamarina $\left(\mathrm{mg} \mathrm{L}^{-1}\right)$ sobre o escoamento do látex e indução de necrose em toda a espessura da casca, aplicadas durante cinco dias consecutivos nos clones de seringueira IPA 1, Fx 4098 e Fx $3864^{(1)}$.

\begin{tabular}{|c|c|c|c|c|c|c|c|c|c|c|c|c|}
\hline \multirow{3}{*}{$\begin{array}{l}\text { Linamarina } \\
\left(\mathrm{mg} \mathrm{L}^{-1}\right)\end{array}$} & \multicolumn{12}{|c|}{ Dias após a aplicação } \\
\hline & \multicolumn{3}{|c|}{2} & \multicolumn{3}{|c|}{4} & \multicolumn{3}{|c|}{6} & \multicolumn{3}{|c|}{10} \\
\hline & IPA 1 & Fx 4098 & Fx 3864 & IPA 1 & Fx 4098 & Fx 3864 & IPA 1 & Fx 4098 & Fx 3864 & IPA 1 & Fx 4098 & Fx 3864 \\
\hline \multirow[t]{2}{*}{0,04} & $\mathrm{~N}$ & $\mathrm{~N}$ & $\mathrm{~N}$ & $\mathrm{~N}$ & $\mathrm{~N}$ & $\mathrm{~N}$ & $\mathrm{X}$ & $\mathrm{N}$ & $\mathrm{N}$ & $\mathrm{XXX}$ & $\mathrm{N}$ & $\mathrm{N}$ \\
\hline & 1 & 0 & 0 & 3 & 0 & 0 & 3 & 0 & 0 & 3 & 0 & 0 \\
\hline \multirow[t]{2}{*}{0,20} & $\mathrm{~N}$ & $\mathrm{~N}$ & $\mathrm{~N}$ & $\mathrm{~N}$ & $\mathrm{~N}$ & $\mathrm{~N}$ & $\mathrm{XX}$ & $\mathrm{N}$ & $\mathrm{N}$ & $\mathrm{XXX}$ & $\mathrm{N}$ & $\mathrm{N}$ \\
\hline & 3 & 0 & 0 & 3 & 0 & 0 & 3 & 0 & 0 & 3 & 0 & 0 \\
\hline \multirow[t]{2}{*}{1,00} & $\mathrm{~N}$ & $\mathrm{~N}$ & $\mathrm{~N}$ & $\mathrm{~N}$ & $\mathrm{~N}$ & $\mathrm{~N}$ & $\mathrm{XX}$ & $\mathrm{N}$ & $\mathrm{N}$ & XXX & $\mathrm{N}$ & $\mathrm{N}$ \\
\hline & 3 & 0 & 0 & 3 & 0 & 0 & 3 & 1 & 0 & 3 & 1 & 0 \\
\hline \multirow[t]{2}{*}{5,00} & $\mathrm{~N}$ & $\mathrm{~N}$ & $\mathrm{~N}$ & $\mathrm{~N}$ & $\mathrm{~N}$ & $\mathrm{~N}$ & $\mathrm{XX}$ & $\mathrm{N}$ & $\mathrm{N}$ & XXX & $\mathrm{XX}$ & $\mathrm{N}$ \\
\hline & 2 & 0 & 0 & 3 & 2 & 0 & 3 & 2 & 0 & 3 & 2 & 0 \\
\hline \multirow[t]{2}{*}{25,00} & $\mathrm{~N}$ & $\mathrm{~N}$ & $\mathrm{~N}$ & $\mathrm{~N}$ & $\mathrm{~N}$ & $\mathrm{~N}$ & $\mathrm{X}$ & $\mathrm{N}$ & $\mathrm{N}$ & XX & $\mathrm{XX}$ & $\mathrm{N}$ \\
\hline & 1 & 1 & 0 & 2 & 3 & 0 & 3 & 3 & 0 & 3 & 3 & 0 \\
\hline \multirow[t]{2}{*}{125,00} & $\mathrm{~N}$ & $\mathrm{~N}$ & $\mathrm{~N}$ & $\mathrm{~N}$ & $\mathrm{~N}$ & $\mathrm{~N}$ & $X$ & $\mathrm{~N}$ & $\mathrm{~N}$ & XX & $\mathrm{N}$ & $\mathrm{N}$ \\
\hline & 0 & 0 & 0 & 0 & 2 & 0 & 3 & 3 & 0 & 0 & 3 & 0 \\
\hline
\end{tabular}

(1)N: ausência de necrose; X: necrose até $10 \mathrm{~cm}$ abaixo do topo; XX: necrose até $30 \mathrm{~cm}$ abaixo do topo; XXX: necrose em todo comprimento do ramo (60 a $80 \mathrm{~cm}$ ); 0 : escoamento normal, a partir da proximidade do topo cortado; 1 : sem escoamento até $30 \mathrm{~cm}$ abaixo do topo; 2 : sem escoamento até $30 \mathrm{~cm}$ abaixo do topo; 3 : sem escoamento em todo o comprimento do ramo $(60$ a $80 \mathrm{~cm})$. 
estão expressos com base na massa de folhas frescas (Tabela 2). Quando calculados com base na massa das amostras secas, tratando-se de folhas jovens, os valores situam-se na faixa de 0,17 a $3,53 \mathrm{mg} \mathrm{CN}^{-} \mathrm{g}^{-1}$ de folha seca, enquanto os apresentados por Lieberei (1988) estão nas faixas de: 1 a $5 \mathrm{mg} \mathrm{CN}^{-} \mathrm{g}^{-1}$ de folha seca, nos clones de HCN-p baixo (PUA 7, PUA 10 e PL 22); de 5 a $10 \mathrm{mg} \mathrm{CN}^{-} \mathrm{g}^{-1}$ de folha seca, nos clones de HCN-p médio (IAN 2829, PB 86, Fx 25) e de 10 a $15 \mathrm{mg} \mathrm{CN}^{-} \mathrm{g}^{-1}$ de folha seca nos clones de HCN-p alto (RRIM 600, IAN 717 e GT1), o que corresponde a 20 até $30 \%$ dos teores de $\mathrm{N}$ considerados altos na análise foliar de seringueira (Shorrocks, 1964).

Em outras espécies cianogênicas, Miller \& Conn (1980) encontraram valores de HCN-p próximos aos da Tabela 2: 0,765, 0,996 e 0,552 mg de HCN por grama de folhas frescas de Phaseolus lunatus, da parte aérea fresca de plântulas de Sorghum bicolor e da parte aérea fresca de plântulas de Linum usitatissimum, respectivamente. Cooke (1978), estudando cianogênese em mandioca, observou que nas duas cultivares com conteúdos mais elevados de cianeto, os teores eram de 0,137 e $0,97 \mathrm{mg}$ por grama de matéria fresca da epiderme e de 0,009 e 0,097 mg por grama de matéria fresca do tubérculo.

As diferenças entre os dados da Tabela 2 e os valores de HCN-p encontrados por Lieberei (1988) são difíceis de explicar, tendo-se em conta que a ati-

Tabela 2. Potencial cianogênico (HCN-p), em mg de cianogênio por grama de matéria fresca, de folhas novas e maduras de clones de copa compatíveis e incompatíveis com o clone de painel IPA 1 , em seringueira ${ }^{(1)}$.

\begin{tabular}{lcc}
\hline Clones & \multicolumn{1}{c}{ Folha nova } & Folha madura \\
\hline & \multicolumn{2}{c}{ Copa incompatível } \\
CNS G 124 & $0,39699 \mathrm{abcA}$ & $0,02097 \mathrm{cB}$ \\
CPAA C 06 & $0,43038 \mathrm{abA}$ & $0,03015 \mathrm{cB}$ \\
CBA 1 & $0,32917 \mathrm{bcdA}$ & $0,01915 \mathrm{cB}$ \\
CPAA C 50 & $0,23214 \mathrm{cdeA}$ & $0,02217 \mathrm{cB}$ \\
CPAA C 14 & $0,20919 \mathrm{deA}$ & $0,01289 \mathrm{cB}$ \\
CPAA C 13 & $0,15389 \mathrm{efA}$ & $0,01315 \mathrm{cB}$ \\
\hline \multicolumn{3}{c}{ Copa compatível } \\
Fx 985 & $0,47941 \mathrm{abA}$ & $0,41577 \mathrm{abA}$ \\
IAN 6158 & $0,30830 \mathrm{bcdeA}$ & $0,26344 \mathrm{bA}$ \\
CPAA C 65 & $0,02895 \mathrm{fA}$ & $0,02128 \mathrm{cA}$ \\
\hline \multicolumn{3}{c}{ Clone de painel } \\
IPA 1 & $0,54201 \mathrm{aA}$ & $0,55349 \mathrm{aA}$ \\
\hline (1)Médias seguidas de mesma letra, maiúscula na linha e minúscula na \\
coluna, não diferem entre si pelo teste de Tukey, a 1\% de probabilidade.
\end{tabular}

Pesq. agropec. bras., Brasília, v. 37, n. 7, p. 925-932, jul. 2002 vidade da $\beta$-glicosidase foi praticamente a mesma da enzima semi-purificada em coluna de Sephadex G 150 utilizada por Lieberei (1986), cerca de 0,2 $\mu \mathrm{mol}$ p-NP $\min ^{-1}$, e que no teste com linamarina houve hidrólise completa, com concentração de linamarina no meio de incubação correspondendo ao HCN-p mais alto relatado por Lieberei (1988).

Por outro lado, para efeito de classificação (baixo, médio ou alto HCN-p), os valores observados para o clone CPAA C 65 de Hevea nitida o classifica como de baixo HCN-p, confirmando os resultados de Lieberei (1988) com essa espécie; além disso, os clones Fx 4512, PL 22, PUA 5 e PUA 9, classificados por Lieberei (1988) como de baixo HCN-p, mostraram-se compatíveis com o IPA 1.

A compatibilidade dos clones de baixo HCN-p reforça a hipótese de incompatibilidade causada por translocação de glicosídeo cianogênico das folhas para o caule. Alguns clones compatíveis apresentaram HCN-p alto nas folhas jovens (Tabela 2). Nesse caso, porém, constatou-se que o HCN-p permanece alto nas folhas maduras, indicando maior tempo de armazenagem nos vacúolos ou menor intensidade de metabolização dos compostos cianogênicos nas folhas, que, de qualquer modo, resultariam em menor exportação desses compostos para o caule.

Os altos valores do HCN-p do IPA 1 nos folíolos jovens e nas folhas maduras mostram que a incompatibilidade é determinada pela translocação, ou não, do glicosídeo cianogênico das folhas, pois, ao contrário, o clone IPA 1 seria uma impossibilidade biológica.

Nos clones incompatíveis, o HCN-p é alto nas folhas jovens e apresenta significativa redução nas folhas maduras (Tabela 2), indicando translocação das folhas para o caule, ou também, presumivelmente, metabolização mais rápida nas folhas que nos clones compatíveis. A ocorrência da incompatibilidade sugere que a translocação deve ser o processo predominante, ou mesmo exclusivo. Nas folhas maduras dos clones incompatíveis, os valores de HCN-p foram relativamente uniformes e não diferiram significativamente, enquanto nas folhas maduras dos clones compatíveis o HCN-p mostrou-se muito variável entre clones (Tabela 2). 
Além do prazo da evolução dos sintomas e da demonstração da atividade de $\beta$-diglicosidase na casca do caule do IPA 1, a inferência de que nos enxertos incompatíveis ocorre o transporte de linustatina das folhas para o caule baseia-se principalmente na impossibilidade do transporte da linamarina, por causa da presença de $\beta$-glicosidase no apoplasma e na conclusão de que o transporte é feito após a transformação da linamarina no diglicosídeo linustatina. Outro indício que também corrobora a hipótese do transporte via linustatina é a presença desse diglicosídeo e a ausência de linamarina no exsudado dos nectários extraflorais dos peciólulos das folhas de seringueira (Selmar et al., 1987), que têm composição semelhante à do fluído dos tubos crivados, bem como no exsudado do endosperma de sementes em germinação, com epicótilo em crescimento, que mobiliza a reserva de $\mathrm{N}$ da semente, pela prévia transformação da linamarina em linustatina, além da ausência de linustatinase no apoplasma da seringueira (Gruhnert et al., 1994).

As evidências apresentadas com os testes de aplicação de KCN e linamarina (Moraes et al., 2001), no estudo das enzimas envolvidas e do potencial cianogênico dos clones de copa e inclusive do IPA 1 apontam de forma convergente para a hipótese do efeito da cianogênese na determinação de incompatibilidade verificada com certos clones de copa enxertados sobre o IPA 1.

Os resultados deste trabalho apontam, além disso, para um fato de alcance bem maior, quando se constata a semelhança dos sintomas da incompatibilidade com os do secamento do painel de sangria descritos por Faÿ \& Hébant (1980). Tal possibilidade torna-se ainda mais plausível, considerando-se que o clone de copa CNS G 124, de alto HCN-p em folíolos jovens e com grande redução nos folíolos maduros, provocou incidência muito alta de secamento de painel quando enxertado sobre painel Fx 4098, logo nos primeiros meses de sangria (Moraes \& Moraes, 1999). Vários autores têm relatado que depois do reenfolhamento anual, quando a copa inteira de plantas adultas de $H$. brasiliensis têm folíolos jovens, de HCN-p mais alto, ocorre incidência mais severa de secamento do painel (Rands, 1921; Volema, 1949; Compagnon et al., 1953; Parajonthy et al., 1975). Os resultados expõem também aspectos novos de interesse no estudo do secamento do painel, com referência ao papel das enzimas estudadas neste trabalho e sua relação com a cianogênese na casca do caule.

\section{Conclusões}

1. A incompatibilidade por translocação em enxertos de copa dos clones sobre o clone IPA 1 é devida à translocação de glicosídeo cianogênico das folhas dos clones de copa, para o caule do IPA 1.

2. A expressão de incompatibilidade das copas, com o IPA 1, está associada a uma atividade muito baixa de $\beta$-cianoalaninassintase na casca do caule.

3. A atividade muito alta de $\beta$-cianoalaninassintase na casca do Fx 3864 o protege dos efeitos da cianogênese, impedindo o acúmulo de HCN livre.

4. Os sintomas de incompatibilidade se assemelham aos de secamento de painel de sangria, indicando o efeito da cianogênese na sua evolução.

\section{Referências}

BLUMENTHAL-GOLDSCHMIDT, S.; BUTLER, G. W.; CONN, E. E. Incorporation of hydrocyanic acid labeled with carbon-14 into asparagine in seedlings. Nature, London, v. 197, p. 718-719, 1963.

BLUMENTHAL-GOLDSCHMIDT, S.; HENDRICKSON, H. R.; ABROL, Y. P.; CONN, E. E. Cyanide metabolism in higher plants. III. The biosynthesis of $\beta$-cyanoalanine. Journal of Biological Chemistry, Bethesda, v. 243, n. 20, p. 5302-5307, 1968.

CASTRIC, P. A.; FARNDEN, K. J. F.; CONN, E. E. Cyanide metabolism in higher plants. V. The formation of asparagine from $\beta$-cyanoalanine. Archives of Biochemistry and Biophysics, San Diego, v. 152, p. 6269, 1972.

COMPAGNON, P.; TIXIER, P.; ROUJAMSKY, G. Contribution a l'étude des accidents physiologiques de saignée. Archief voor der Rubbercultuur in Netherlandische-Indie, Bogor, v. 30, p. 54-69, 1953. Supplement.

COOKE, R. D. An enzymatic assay for the total cyanide content of cassava (Manihot esculenta Crantz). Journal of the Science of Food and Agriculture, Chichester, v. 29, n. 4, p. 345-352, 1978.

DIJKMAN, M. J. Hevea: thirty years of research in the far east. Coral Gables: University of Miami Press, 1951. $329 \mathrm{p}$.

FAŸ, E. de; HÉBANT, C. Étude histologique des écorces d'Hevea brasiliensis atteintes de la maladie des encoches sèches. Comptes Rendu de l'Académie de Sciences, Série D Sciences Naturales, Paris, v. 291, n. 10, p. 865$868,1980$. 
FLOSS, H. G.; HADWIGER, L.; CONN, E. E. Enzymatic formation of $\beta$-cyanoalanine from cyanide. Nature, London, v. 208, n. 5016, p. 1207-1208, 1965.

GOUDEY, J. S.; TITLLE, F. R.; SPENCER, M. S. A role for ethylene in the metabolism of cyanide by higher plant. Plant Physiology, Rockville, v. 74, n. 4, p. 1306-1310, 1989.

GRUHNERT, C.; BIEHL, B.; SELMAR, D. Compartmentation of cyanogenic glucosides and their degrading enzymes. Planta, Berlin, v. 195, n. 1, p. 36-42, 1994.

LIEBEREI, R. Cyanogenesis of Hevea brasiliensis during infection with Mycrocyclus ulei. Journal of Phytopathology, Berlin, v. 115, n. 2, p. 134-146, 1986.

LIEBEREI, R. Relationship of cyanogenic capacity (HCN-c) of the rubber tree Hevea brasiliensis to susceptibility to Microcyclus ulei, the agent causing South American leaf blight. Journal of Phytopathology, Berlin, v. 122, p. 56-57, 1988.

MILLER, J. M.; CONN, E. E. Metabolism of hydrogen cyanide by higher plants. Plant Physiology, Rockville, v. 65 , n. 6 , p. 1199-1202, 1980.

MORAES, L. A. C.; MORAES, V. H. de F.; CASTRO, P. R. de C. e. Aplicação de KCN e linamarina e a incompatibilidade de enxertia por translocação no clone de seringueira IPA 1. Scientia Agricola, Piracicaba, v. 58, n. 4. p. 717-723, 2001.

MORAES, V. H. de F. Enxertia de copa para a remoção dos impedimentos naturais à heveicultura na Amazônia sempre úmida. Manaus: Embrapa-CPAA, 1999. 12 p. Relatório final do subprojeto (070.94.018.01), do programa (07) - sistema de produção de matérias primas.

MORAES, V. H. de F. Sumário das pesquisas sobre enxertia de copa da seringueira no CPAA. Manaus: Embrapa-CPAA, 1997. 25 p. (Documentos, 8).

MORAES, V. H. de F.; MORAES, L. A. C. Secamento do painel de sangria do clone de seringueira $F x 4098$ (Hevea brasiliensis) sob copa enxertada de H. pauciflora: correlação com teores de magnésio no látex e resposta a dose suplementar de magnésio. Manaus: Embrapa-CPAA, 1999. 6 p. (Comunicado Técnico, 3).

MORAES, V. H. de F.; MORAES, L. A. C. Seleção precoce de clones de copa e de painel de seringueira para experimentos de avaliação de clones com copas enxertadas. Agrotrópica, Itabuna, v. 8, n. 1, p. 23-26, 1996.
MORITA, T.; ASSUMPÇÃO, R. M. V. Manual de soluções, reagentes e solventes. São Paulo: E. Blücher, 1990. 627 p.

PARAJONTHY, K.; GOMEZ, J. B.; YEANG, H. Y. Physiological aspects of brow bast development. In: INTERNATIONAL RUBBER CONFERENCE, Kuala Lumpur, 1975. Proceedings... Kuala Lumpur: Rubber Research Institute of Malaysia, 1975. p. 181-202.

PEISER, G. D.; WANG, T. T.; HOFFMAN, N. E.; YANG, S. F.; LIU, H. W.; WALSH, C. T. Formation of cyanide from carbon 1 of 1-aminocyclopropane1-carboxylic acid during its conversion to ethylene. Proceedings of the National Academy of Sciences of the United States of America, Washington, v. 81, n. 10, p. 3059-3063, 1984.

PIMENTEL-GOMES, F. Curso de estatística experimental. Piracicaba: Nobel, 1990. 468 p.

RANDS, D. Brown-bast disease of plantation rubber, its causes and prevention. Archief voor der Rubbercultuur in Netherlandische-Indie, Bogor, v. 5, p. 54-69, 1921.

SCOTT, W. W. Standard methods of chemical analysis. New York: D. van Nostand, 1939. 2617 p.

SELMAR, D. Cyanogenese in Hevea Zwei Wege zur Metabolisierung cyanogener Glucoside. 1986. 171 p. Thesis (Ph.D.) - Technische Universität Carolus Wilhelmina zur Braunschweig, Braunschweig.

SELMAR, D. Transport of cyanogenic glucosides linustatin uptake by Hevea cotyledons. Planta, Berlin, v. 191, p. 191-198, 1993.

SELMAR, D.; LIEBEREI, R.; BIHEL, B.; VOIGT, J. Hevea linamarase: a nonspecific $\beta$-glycosidase. Plant Physiology, Rockville, v. 83, n. 3, p. 557-563, 1987.

SHORROCKS, V. M. Mineral deficiencies in Hevea and associated cover crops. Kuala Lumpur: Rubber Research Institute of Malaysia, 1964. 76 p.

UMBACH, H. $\beta$-cyanoalanin synthase in Hevea species. Braunschweig: Technische Universität Carolus Wilhelmina zur Braunschweig, 1989. 76 p.

VOLEMA, J. S. Einige waarnemingen over het optreden de bruine binnen bastziekte. De Bergcultures, Bogor, v. 18, n. 1, p. 181-202, 1949. 